\title{
Downside Risk-Return Volatilities During Covid 19 Outbreak: A Comparison Across Developed and Emerging Markets.
}

syed asim shah ( $\sim$ sashah@numl.edu.pk)

National University of Modern Languages https://orcid.org/0000-0001-6803-5486

Hassan Raza

Shaheed Zulfikar Ali Bhutto Institute of Science and Technology

Aijaz Mustafa Hashmi

National University of Modern Languages

\section{Research Article}

Keywords: Covid 19, Downside Risk, Value at Risk (VaR), Risk Simulation, Equity Markets

Posted Date: February 4th, 2022

DOl: https://doi.org/10.21203/rs.3.rs-1183394/v1

License: (c) (1) This work is licensed under a Creative Commons Attribution 4.0 International License.

Read Full License 


\section{Abstract}

This research study evaluates the impact of the covid 19 pandemics on the downside risk-return volatilities across the four stock markets of the USA, UK, China and Pakistan. The pandemic results in severe economic and financial consequences both at micro and macro levels as well as across the stock markets of various countries. The selected stock markets of the USA, UK, Pakistan and China are significantly affected in terms of both investor risk and return during the pandemic time. The entire period distribution of the risk exhibited the downside risk behaviour of both markets and investors serious concern regarding their investment strategies. Using high-frequency data from January-2020 to April 2021 , the findings of the study reveal more of the downside abnormal returns across both markets. The impact of larger and high in developed markets of USA and UK compare to the emerging markets of China and Pakistan. The outcomes of the various VaR models discloses the higher downside risk implications for all markets, larger for developed countries. Similarly, the three stock markets of the USA, UK and China were found to be significantly connected during a pandemic. Investor's reactions were positive and high in case of positive news outbreaks and dwindling in case of negative news and downside impact. The outcomes of the study are useful for investors, portfolio managers, investment advisors and others to understand the dynamics of the pandemic situation and devise effective strategies to overcome the severities of downside risk.

\section{Introduction}

The equity markets have always been volatile, and it is exposed to both unsystematic and market risk. On some level, the risk is unavoidable and compulsory to generate substantial profits. However, if it reaches a certain point, it will result in calamity. If the returns are favorable, it is not a major worry; but, if they are negative, it has a significant impact on investors and the economy's functioning. Researchers have devoted a lot of time and effort to studying stock market behaviour, particularly during crises. Stock markets, according to Carp (2012), may impede economic progress because of their market failure susceptibility due to crisis. Health catastrophes are regarded as more significant since they affect both people's lives and the economy as a whole.

Furthermore, due to the interconnected features of global markets after globalization, Chiang et al. (2007), Sun and Hou (2018), and Morales and Andreosso-O'Callaghan (2012) corroborate that instability in one particular equity market is substantially associated with the instability in other equity markets. As a result, bad news from a foreign market impacts not just that country's market but also markets in other nations and asset classes. When there is no plan for contingencies, as in the instance of COVID-19, which has left the globe traumatized, it is serious. On December 31, 2019, the first case of COVID-19 was reported in Wuhan, China. The World Health Organization (WHO) declared it a Public Health Emergency of International Concern on 30 January 2020, even though it was not taken seriously at first. The WHO deemed this to be an urgent global public health emergency with fast increases in infection even after travel prohibitions in China. Happening March 11, 2020, the WHO delayed nearly two consecutive months to designate COVID-19 as a worldwide contagion. This unwelcome and unexpected occurrence has had 
an impact on every area of the global economy. Because the Republic of China is the world's leading producer and trader of world crude oil, economists have predicted a slowing of their development (Sohrabi et al., 2020). The condition is rapidly deteriorating, and the deadly sickness had to transmit to the other countries and regions of the world, killing more humans than in China. The governments of the majority of countries impacted by the virus are implementing a variety of steps, including public place lockdowns and closures, compensation for employers, and tax reductions.

In the event of a health-related crisis, the situation becomes much more perilous since the economic activity is halted. As of now (May 2020), it has affected 59, 20, 231 individuals worldwide and claimed the lives of about 3,62,365 people (Worldometer). Forecasts for employment and GDP have reached new lows. Furthermore, financial sector participants are restricting their investments. Agricultural goods have seen a $20 \%$ reduction in price (Bhosale, 2020, March 19). The British Public Federation on March 20, 2020, expressed worry about a large drop in industrial turnover in the various sectors in the United Kingdom. During the H1N1 virus pandemic in Taiwan, 18 per cent of families lost income as a direct consequence of the impact on the education sector (Chen et al., 2011). As a result of the closure of educational institutions due to the COVID-19, country-wise 900 million pupils are tormented released in the report by UNESCO on March 24, 2020. COVID-19 pandemic, according to Nicola et al. (2020), has also resulted in a geopolitical battle over oil output between Russia and OPEC nations. COVID-19, to put it bluntly, has stemmed the world to the impeding dogma of the greatest crises of history.

Based on the frightening cases from the COVID-19, the effects of the previous crisis on the world economy, the devastating repercussions of the COVID-19, and the relevance of stock market indexes to reflect an important economic dimension, we are attempting to conduct a scientific assessment on the stock market indices of the world's leading economies representing developed and emerging block. Favorable and unfavorable ups and downs in the stock markets are investigated during the period of the COVID-19 era and relative to other time periods with significant stock market volatility using different variants of the augmented Value-at-Risk models. In addition, our study tried to figure out how different marketplaces interact with one another during pandemic crises periods. How the market participant reacts to downside risk volatilities, how they retransform their strategies to safeguard such crises situations.

The entire study of our is organized around five sections. Section one was the introduction and theoretical background. The second section elaborates the review of past studies, third report the research design and methodology to empirical test the main hypothesis. Section four report the empirical findings of the study, while the last section reports the conclusion, implications and limitations of the research study.

\section{Review Of Empirical Studies}

Contingency effects usually decrease prediction and prevention. This involves a comprehensive examination of past occurrences to seek certain patterns or indications for future action. In reaction to 
contingency, especially negatives, researchers, economists and market analysts are continually reviewing how the markets and the economy operate. The economic consequences of the contagions and global health diseases are huge, not confined toward the affected nations according to Lee \& McKibbin (2003), in his research findings examined the economic and financial consequences of the SARS disease. In the chemical, building, departmental, food, hotels, textiles and car industries in Taiwan, there are constant negative returns (Chen et al., 2005). The losses in financial markets equal \$2 trillion in equity in De Lisle (2003) almost comparable to the Asian financial crisis. The cost of influenza economics in the United States was estimated by Meltzer et al (1999) to range from US\$73.1 million to US\$166.5 million. Blowoms et al. (2005) considered the effects of the contagion owing to the conversion of an avian infection strain in human bodies and concluded that the world's economic development and world commerce fell, respectively, by 0,6 and 14 per cent, based on 20 per cent occurrence rate and 0.5 per cent death rate causing the huge number of causalities in affected areas.

The harmful short-term effects of H1N1 flu from 2009 in Mexico were also reported by Rassy \& Smith (2013). The economic cost of McKibbin \& Sidorenko (2006) has been forecast as US\$300 million to US\$4. 4 trillion, taking account of three mild or severe pandemic scenarios. On 28 February 2020, Mike Patton, Senior writer at Forbes, said that in the worst-case case scenarios of Spanish flu was a $21 \%$ drop, but in the first half of the year, the swine flu was up by $40 \%$, as the stock had already been undervalued by the worldwide crisis (Patton, 2020). However, several researchers did not find particularly severe stock market impacts. The market indexes of three Latin American and Caribbean nations except for Brazil have not shown significant adverse returns during the epidemic of the Zika virus in Macciocchi et al (2016). A similar behaviour during the Spanish flu was seen by Velde (2020). The reported downfall was enormous throughout the period of the worldwide crisis in India, according to Kumar (2020), with Nifty falling 65 per cent from the high but a widening time horizon. In just a few days, the worldwide epidemic collapsed $30 \%$ and $32 \%$ of Indian and U.S. stock markets correspondingly. However, Valigra (2020) declared that the financial markets generally correct themselves following the epidemics, when it referenced S\&P 500-18.72\% and 35.96\%, respectively, of swine influenza, within 6 months and 1 year.

Jenny (2020) adds that during the time of contagion majority community can perform work duties. As a result, the monetary cost of COVID-19 would be considerably higher than the 2008 global crisis, and the Western nations can lose around 15 per cent of their GDP in the near run. The economic costs of the COVID-19 containment approach would, according to Ferguson et al. (2020), be substantial. It's the only way to rescue the world, however. A USD 14 billion quick track funding plan has been agreed by the World Bank Group to assist firms and nations react to the Covid-19 spread (llyas, 2020). Baker et al. (2020) reported around 18 leaps in 22 days were recorded, more jumps than at any other period in history when analyzing the stock market swings via documenting ups and downs in these markets by more than $2.5 \%$. Jorda et al. (2020) specified over a long-term period of eras with declining investment possibilities trails epidemics because of the dread of devaluation, loss of money, and over-capital recovery per unit of enduring labor when examining the influence of pandemics on real interests' rates. They also anticipated, however, that the outcome might be different this time, as the bulk of those afflicted by the past pandemics are less than 60 years old and if small interest supports over a longer period of time, it can be 
useful in helping governments to ease COVID-19 costs. In addition, the epidemic leads toward geopolitical warfare for the countries of China and the United States (Hartl et al., 2020). Centrum Broking's Equities Chief Investing Officer, Anil Sarin, put up his thoughts on investment strategies and said that in addition to instability on other markets as a result of the raw crude oil mandate a significant conflict between Saudi Arabia and Russia. As a result, the equity market of the USA has plummeted by greater than 20 per cent.

The decrease in capital markets was seen by McKibbin and Fernando (2020) owing to COVID-19 and by investors, demand and other risk factors arise. Transferring their money to other assets and places they feel innocuous. Liu et al. (2020) investigated lately the equity markets in COVID-19 nations concerned and established that there was equity markets impact by the virus substantially and adversely. In addition, it was established that the rates of indexing decreased the most by approximately 0.01 for France, Germany, Russia, Italy, Thailand, the UK, Canada, Japan, the USA, India, Abu Dhabi and Australia, and those for Singapore, Thailand, Korea, Indonesia and Hong Kong decreased the highest by $325,245 \%$, $274,619 \%, 115,163 \%, 64,345 \%, 49,086 \%$. The transmission of baffling COVID-19 can be decreased by societal separation, as indicated by Prem et al. (2020) nevertheless, its effects vary across various age categories. Atkenson (2020) further expresses worry that the disease can spread fast throughout the world within less than 18 months if attempts to mitigate the sickness are loosened.

The literature outlines several risk steps, but $\mathrm{VaR}$ is one of the finest and commonly followed since it does not complicate a single measure. It also helps to discover the risk of adverse effects. VaR is the primary measure for calculating the risks of the market (BCBS, 2006). JP Morgan \& Reuters created VaR in 1994 - Risk metrics and successful results were seen. Many other industries started to use their market risk calculation afterwards. As Linsmeier \& Pearson (2000) has developed, the emergence of VaR as a risk measure was driven by large fluctuations in important economy-related indicators and the growing usage of derivatives. As to Jorion (2002, p. 911), VaR is able to encapsulate in a single dollar that is easily communicated the impacts of leverage, diversification and probability of unfavourable price shifts. Accordingly, the specified model is the prime measure of downside risk for various groups of statistical continuous distributions, asserted Gaglianone et al. (2011). VaR became more common in the banking sector and was used to calculate the capital adequacy ratio in the context of a risk measure, after the required adoption of VaR by the Basel Committee on Banking Supervision in April 1995. (Jorion, 1996). VaR was also proposed by the Securities and Exchange Commission in December 1995 to replace listed US CRPBs. Also, proponents of VaR are Jorion (2002), Uylangco and Li (2015, Xu (2017), but attentively. Most research with VaR focuses on evaluating the risk of the banking industry and on improving the methodology and back-testing the various models. Swami et al. (2016) are generally underestimated with estimates of $\mathrm{VaR}$ foreign exchange in India which have been reached based on traditional standard methods. Sarma et al. (2003) proposed that users select various VaR models depending on distribution for distinct portfolio estimates. Chinhamu et al. (2015) reviewed both short- and long-term trading profits and losses on the Chinese gold market and observed that the precise VaR estimate depends on the adequacy of extreme data exposures. 
After studying and recognizing the pertinent empirical literature and severity of pandemic impact on equity markets, our study aims to analyze the dynamics of the stock market in emerging and developed economies worldwide in terms of downside risk-return volatilities. Because it is widely utilized for market downside risk assessment, VaR and its variant models were used to study the downside risk dynamics of selected markets. Our study answers the following research questions:

What is the impact of the Covid-19 pandemic on the downside risk volatilities of the selected markets? How markets will react? Which market is more exposed relative to other markets?

\section{Research Design And Methodology}

Our study draws the comparison of assessing the downside risk and relative returns across four countries during the pandemic period. We have selected the Pakistan, US, UK and China stock markets as these countries are significantly dazzled by the COVID-19 shocks and are the leading nations in the comparison of risk-return volatilities with worldwide partners. The stock indexes undertaken for the empirical analysis are KSE-100-Pakistan, S\&P 500-USA, FTSE-UK and SSE-China. According to Pearce (1983), stock price disparities can be anticipated to affect collective expenditure and, hence, economic direction. Therefore, in our study, we have regarded stock market indices as a major economic indicator. The selected economies are the world's top economies, with COVID-19 creating significant downside volatilities across these markets. We used high-frequency data from January 2020 to April 2021 to analyze the impact of the Covid 19 pandemic on the downside risk patterns across these markets. These downside risk volatilities result in a significant worth of losses for investors and impact the economies at a larger scale. Since the Covid-19 is not yet over, the data and results may be obsolete if there is a change in the pattern of illness. However, from 1 January 2020 to April 2021 we use a limited data period as a Covid-19 period. This is because, in October 2019, the first official Covid-19 case was recorded. Secondly, we examine upside volatility and downside volatility for chosen economies during the Covid-19 pandemic. This time period was selected based on data availability and homogeneity across the sample economies. Various econometric techniques were applied to calculate and analyze the downside risk volatilities including, VaR models, risk simulations and trend analysis. The purpose is to study whether the pandemic has significant implications for various investors, managers and policymakers to hedge and overcome negative outcomes due to downside risk caused by the pandemic. Data were obtained from the different national and international market indexes' official websites including data stream and yahoo finance. Additional information about Covid-19 was obtained from the different nations' Ministry of Health repositories of the concerned nations.

\section{Computation of Return Volatility}

We begin our analysis with the calculation of return volatility for each market during the pandemic and the findings exhibit the significant downside volatilities that indicate the presence of larger downside risk. However, we present both positive as well as overall trends relative to negative trends exhibiting the presence of downside risk due to pandemics across all four selected markets. 


\section{Modelling Return Volatilities}

\section{Parametric Value at Risk (PVaR)}

In the first variant of the VaR model, we estimated VaR in the first step, for all selected markets and also the total time to observe the downside risk. Throughout a given period, the value at risk approach (VaR) is a standard method of counting the biggest probable loss. Variance-Covariance Method (parametrical $\mathrm{VaR}$ ) or parametric value at risk (PVaR) are the most used way of VaR. The returns should be independent and distributed identically in accordance with this technique based on the premise of normal distribution. The parametric value at risk (PVaR) is specified as:

$$
\operatorname{VaR}_{\mathrm{p}}=\mu-\mathrm{z}^{-1} \sigma
$$

The terms $\mu$ and $\sigma$ represent the arithmetic mean (AM) and deviation around the mean (SD) of the selected time series based on the $99 \%$ interval level. Whereas $\mathrm{z}^{-1}$ measures the converse of the properties of the given function based on the normal distribution.

\section{Student T-Value at Risk (TVaR)}

In the second variant, we estimated the TVaR to observe more the deep fluctuations in the returns during the pandemic to observe the downside volatilities. However, as the return series is generally observed to have tall peaks and even tails, and meanwhile the sampling size of the regime is limited, our study has additionally calculated VaR to incorporate more tail events. The properties of TVaR are defined as:

$$
\operatorname{VaR}_{\mathrm{ST}}=\sqrt{\mathrm{v}^{-1}(\mathrm{v}-2)} \mathrm{it}_{\mathrm{v}}^{-1}(1-\alpha) \sigma-\mathrm{h} \mu
$$

In the given equation $\mathrm{VaR}_{\mathrm{ST}}$ denotes the TVaR and the term $\mathrm{v}$ describe the degrees of freedom for the students t-distribution.

\section{Monte Carlo Simulation}

Simulation generally offers the proper path in case the given data set is not identically distributed (Uylangco \& Li, 2015). To perform robustness measures, check over the conduction of the VaR model our study applied the Monte Carlos Simulation for the entire sample period of the study. The specified model is:

$\mathrm{I}_{\mathrm{t}+1}=\mathrm{I}_{\mathrm{t}} \exp \left[\mathrm{rf}-\frac{\sigma^{2}}{2 \sigma \mathrm{y}^{\prime}}\right]$

In the given equation $\mathrm{I}_{\mathrm{t}}$ denote the current price of the given stock at time period $\mathrm{t}$, the term $\mathrm{r}$ is the measure of the risk-free rate of return, $\sigma$ measures the standard deviation of the targeted index returns, and $y^{\prime}$ represents the normally distributed random variable consist of 0 mean and unit standard deviation. In this study, we adopted the arithmetic variate method of Boyle (1977) and employed 
techniques of variance reduction to decrease simulation errors. We have generated 100,000 simulated equity prices randomly to experiment with the test of VaR to examine the risk volatilities on different returns.

\section{Isolation of Positive and Negative Returns}

In our study analysis, the description of the volatility indicates that the anticipated return has deviated. The difference might be favorable or negative. Investors are worried that their investment value is being lost as it produces negative volatility. But both the favorable instability and the unfavorable instability in our study designed were considered. In analyzing each country's benchmark returns, we have built two distinct clusters. One group is divided by positive returns while the other is divided by negative returns. We tried, using the following formula, to determine the maximum gains measured by (MPG) and maximum potential losses measured by (MPL) for both groups:

MPG or MPL $=\mu \pm 2.33 \sigma \times$ af

af $=\sqrt{\mathrm{v}^{-1}(\mathrm{v}-2)} \frac{\mathrm{T}^{-1}(\alpha, \mathrm{v})}{\mathrm{N}^{-1}(\alpha)}$

In the given equations $\sigma$ and $\mu$ represents the standard deviation and mean at $99 \%$ significance level, the term $v$ describe the student's distribution number of degrees of freedom and symbol $\mathrm{N}^{-1}$ is the converse function of the entail t-distribution. Our study also estimated peaks and dips in the case of positive and negative clusters, by calculating the returns smaller than the MPG and MPL.

\section{Back-testing}

For the purpose of back-testing, Kupiec's test is utilized. The second term for the test Kupiec likelihood ratio (LR) is the POF test ratio that indicates the percentage of failures. Essanciano and Olmo (2018) described back-testing as the procedure in which the actual trading outcome is compared relative to the model produced risk metrics. The test of Kupiec evaluates the loss frequency above the value of VaR. As to Chinhamu et al. (2015, p. 113), the ensuing technique contains in its calculation the number of times the rates of failure measured decline under (in long-standing spots) or over (for short-standing spots). The testing null hypothesis measures the expected fraction of violations relatively equivalent to $a$. If the number of observations is $\mathrm{N}$, the number of violations is $\mathrm{a}$ and the resulting assurance interval is $\mathrm{a}$; then estimated POF is $\rho$ and it would be specified as $\mathrm{a}=\rho=\mathrm{V} / \mathrm{N}$. The LR is calculated as follows:

$$
\mathrm{LR}_{\rho}=2 \ln \left[\frac{1-\alpha^{\mathrm{N}-\mathrm{V}} \alpha^{\mathrm{V}}}{\left[1-\left(\frac{\mathrm{V}}{\mathrm{N}}\right)^{\mathrm{N}-\mathrm{V}}\left(\frac{\mathrm{V}}{\mathrm{N}}\right)^{\mathrm{V}}\right]}\right]
$$


In the specified equation the term in the upper division entails the maximum likelihood of the realized outcomes according to the non-alternate hypothesis and the term in the lower division entail the maximal likelihood of the realized ratio as per the alternate hypothesis reported in the study of (Patra and Padh, 2015).

\section{Discussion Of Empirical Findings}

Beginning our analysis with the estimation of downside exposure, table 3 display the findings of the risk estimation models based on PVaR, TVaR and SVaR of the equity market earnings of four economies. Among four selected markets, S\&P-USA reports the highest of the risk, FTSE UK the second highest, KSEPakistan third highest and SSE-China the lowest among four markets. Except for the USA, the other three markets exhibit the downside risk between $4-12 \%$, but the S\&P USA risk stand at $14.336 \%, 8.962 \%$ and $8.677 \%$ according to SVaR, TVaR and PVaR reported values. The S\&P index representing the US equity platform turns out to be the highest downside risk market for investors relative to the others during the pandemic time period. But, although COVID-19 originated in China, it is extremely unusual to discover the SSE Chinese equity market is so robust and less obstructed. That might be why international leaders accuse China of having launched a biological war. But China's excellent pandemic management approach might be the explanation behindhand by the lesser influence of COVID-19 on the Chinese equity market.

Whilst risk measure $(\mathrm{VaR})$ is viewed as the systematic model to estimate the market risk, the real risk still exceeds the expected $1 \%$ chance (when counting VaR in $99 \%$ significance level). The results are therefore extremely useful to Back-test. In the initial analysis, we compute the number of VaR breaches. The lower the infringement, the better the estimate. We count the infringement if the index return is lower than the VaR estimate. In addition, standard Kupiec's LR correspondingly shows the exactness of the method. According to the findings of the Kupiec's test reported in table-1 below, the different variants of VaR models were constructed to be correct over the targeted sample period. Among these models, SVaR stands to be the utmost correct model. Since the distribution of the returns stream is not quite normal and the LR of Kupiec is lower for SVaR in every system, SVaR might stand as the best model. The findings of our study are consistent with Das \& Rout, (2020) and Li, (2021) reporting the significant influence of the covid-19 epidemic on the equity market exposure exhibiting the downside risk volatilities.

Table 1: Downside Risk based on Various Models 


\begin{tabular}{|lllll|}
\hline & KSE-Pakistan & S\&P USA & FTSE UK & SSE China \\
\hline Mean & -0.160 & -0.134 & -0.242 & -0.173 \\
\hline SD & 1.970 & 1.980 & 2.899 & 1.988 \\
\hline PVaR & -4.980 & -8.677 & -6.899 & -4.122 \\
\hline TVaR & -5.113 & -8.962 & -7.133 & -4.872 \\
\hline SVaR & -5.344 & -14.336 & -12.248 & -5.016 \\
\hline
\end{tabular}

Table 2: Violations from VaR Models

\begin{tabular}{lcccc}
\hline & KSE-Pakistan & S\&P USA & FTSE UK & SSE China \\
\hline Viol.pVaR & 1 & 3 & 2 & 2 \\
Viol.sTVaR & 1 & 3 & 2 & 2 \\
Viol.sVaR & 0 & 0 & 0 & 0 \\
\%Viol.pVaR & 1.171 & 3.445 & 2.338 & 3.016 \\
\%Viol.sTVaR & 1.171 & 3.445 & 2.338 & 3.016 \\
\%Viol.SVaR & 0 & 0 & 0 & 0 \\
KUPIEC.PVaR & $0.040^{* *}$ & $3.887^{* *}$ & $1.899^{* *}$ & $3.098^{* *}$ \\
KUPIEC.STVaR & $0.040^{* *}$ & $3.887^{* *}$ & $1.899^{* *}$ & $3.098^{* *}$ \\
KUPIEC.SVaR & $0^{* *}$ & $0^{* *}$ & $00^{* *}$ & $0 * *$ \\
\hline
\end{tabular}

\section{Violations against overall Simulated VaR}

In this phase of the study, we compute the SVaR violations of each market from SVaR throughout the whole time period. This is done to evaluate the period of highest volatility over the four identified stock markets. The greater the violation proportion, the greater the risk. It is evident in Table 3 that the percentage violation is highest in the USA market, second highest in the UK market and Pakistan and China market exhibit the same quantity of violations. The data suggest the gravity of the COVID-19 phase in a time that is so high in the globe. But China's case is startling. Similarly, in the case of the Pakistani market, the dazzling effect of the pandemic is not so severe and downside risk volatilities appear to be low in peak relative to the USA and UK stock market.

Table 3: Violation from Simulated VaR Model

\begin{tabular}{|lllll|}
\hline & KSE-Pakistan & S\&P USA & FTSE UK & SSE China \\
\hline Viol. & 2.000 & 13.000 & 8.000 & 2.000 \\
\hline \%Viol. & 2.118 & 15.337 & 8.449 & 2.997 \\
\hline
\end{tabular}


In this section of the study, we segregate the returns into negative and positive chunks for in-depth analysis to see separate volatilities resulting in both upside and downside risk. The findings reported in the table below indicate more negative returns than positive returns during the pandemic period, which means the investors were exposed to more of the downside risk in that time period than the upside risk. The likelihood of earning more of the losses is higher in the pandemic period. Pakistan and China had the highest MPG in the case of positive return regime and the USA and UK had the highest MPL in negative return regime. These findings indicate the presence of more downside risk volatilities for the USA and UK stock markets relative to Pakistan and China stock markets during the pandemic time period. The jumps and percentage of jumps were also highest in the case of US and UK stock markets than the other two markets. This concludes the presence of higher downside risk for US and UK investors relative to Pakistan and China investors in line with Zhang, Hu, \& Ji, (2020).

Table 4: Summary of Positive Return

\begin{tabular}{|lllll|}
\hline & KSE-Pakistan & S\&P USA & FTSE UK & SSE China \\
\hline Mean & 1.482 & 0.788 & 0.977 & 1.299 \\
\hline SD & 0.893 & 0.522 & 0.858 & 0.944 \\
\hline MPG & 4.031 & 1.811 & 2.663 & 3.778 \\
\hline Jumps. & 2 & 1 & 2 & 2 \\
\hline \% Jumps. & 1.997 & 0.564 & 1.616 & 1.595 \\
\hline
\end{tabular}

Table 5: Summary of Negative Returns

\begin{tabular}{|lllll|}
\hline & KSE-Pakistan & S\&P USA & FTSE UK & SSE China \\
\hline Mean & -1.447 & -3.779 & -2.337 & -1.994 \\
\hline SD & 1.399 & 3.006 & 1.877 & 1.587 \\
\hline MPL & -6.001 & -11.770 & -7.988 & -6.117 \\
\hline Jumps. & 5 & 16 & 15 & 7 \\
\hline \% Jumps. & 12.033 & 33.772 & 34.556 & 12.887 \\
\hline
\end{tabular}

\section{Market Integration and Interdependence}

Since the markets are connected in the era of globalization, it is extremely necessary to verify before the planning of investments the association between the different markets since it gives a view of the strategy of diversification. The connection between the four countries stock markets is reported in the correlation matrix below.

The correlation matrix exhibits a significant positive correlation among the four markets. The stock returns of the USA were highly and significantly associated with UK and China and the UK with China. 
The returns of the Pakistan market are insignificant and minimally correlated with the other three markets of the USA, UK and China. These findings indicate the market interdependence among the USA, UK and China exist and prevail during the period of the risk of the pandemic that largely affects the other nations and related stakeholders.

Table 6: Correlation Matrix

\begin{tabular}{|lllll|}
\hline & KSE-Pakistan & S\&P USA & FTSE UK & SSE China \\
\hline KSE-Pakistan & 1.000 & & & \\
\hline S\&P USA & 0.049 & 1.000 & & \\
\hline FTSE UK & 0.053 & $0.776^{\star \star \star}$ & 1.000 & \\
\hline SSE China & $0.337^{\star \star \star}$ & $0.484^{\star \star \star}$ & $0.396^{\star \star \star}$ & 1.000 \\
\hline
\end{tabular}

\section{Conclusion And Implications}

The global community has reached an era in which human beings fear talking, working, eating and not talking to each other. In this study the influence of COVID-19 on equity market indexes of four economies, using VAR models, has been tested and analyzed. The findings of the study show that the volatility of stock markets was considerably affected by COVID-19. It is noted that in the COVID-19 era the MPL of all four countries was the greatest in such a short time. This makes the situation far more frightening than the other financial crises of different time periods. Relative to China and Pakistan, the VaR from the regime was likewise the greatest in the USA and UK which is very unanticipated because the disease began in the state itself. In this system, particularly in Pakistan and China, violation of the MPL has also been most serious but less relative to the USA and UK. In addition, in the COVID-19 era, the market correlation is likewise the greatest except in Pakistan. But a sigh of relief may be raised because the markets also showed a favorable return if the administration tried certain political steps to deal with the problem. Investors community nevertheless usually risks being ignorant, and our research study has also demonstrated that the recipient reacts to bad news rather than to favorable news. This also indicates the herding behaviour in addition to the serious reaction toward risk volatilities.

The impact of this form of the pandemic is difficult to predict, as vaccination is in process with different variants of virus are still emerging, so it is still not foreseeable. The drawback of our analysis is that the stock market behaviour may alter if the pace of the epidemic changes or if a treatment may be found. Therefore, our study mainly examined the short-term influence. Investors and regulators would be helped to foresee the potential of risk in similar conditions by knowing the short period fluctuations of the stock market. The present research can further enable equity market contestants from many regions of the globe to structure their asset management strategies by monitoring and therefore diversify their portfolios by the degree and directions of the connection between different markets. Government and regulators can also, after thorough observation, adopt actions to improve investor confidence. 


\section{Declarations}

\section{- Ethical Approval}

It is solemnly declared that the research does not violate any ethical standards of any sort with regard to involvement of research participants, data collection, research write-up, acknowledgment of sources and other areas of concern in ethical domain.

\section{- Consent to Participate}

The data has been collected from secondary open-source database. The data is available to everyone and is free for use and does not require any consent. The researchers provide consent for its use for future references with proper citations.

\section{- Consent to Publish}

The authors provide their consent for lawful publication of the research with proper citation and acknowledgements.

\section{- Authors Contributions}

1. Dr. Syed Asim Shah: Idea conception, initial data gathering, theoretical background, problem statement and write up

2. Dr. Hassan Raza: Data analysis and interpretation

3. Dr. Aijaz Mustafa Hashmi: Research design, data collection and proof review.

\section{- Funding}

Not Applicable as the research is not funded by any organization.

\section{- Competing Interests}

The research and the researchers have no competing interests of any sort.

\section{- Availability of data and materials}

The data has been collected from secondary open-source database. The data is available to everyone and is free for use and does not require any consent. The researchers provide consent for its use for future references with proper citations. Also the data analyzed can be provided upon request.

\section{References}

1. AlTakarli NS (2020) China's response to the COVID-19 outbreak: A model for epidemic preparedness and management. Dubai Medical Journal 3(2):44-49 
2. Anderson RM, Heesterbeek H, Klinkenberg D, Hollingsworth TD (2020) How will country-based mitigation measures influence the course of the COVID-19 epidemic? The lancet 395(10228):931934

3. Ashraf BN (2020) Stock markets' reaction to COVID-19: Cases or fatalities? Research in International Business and Finance 54:101249

4. Atkeson A (2020) What will be the economic impact of COVID-19 in the US? Rough estimates of disease scenarios (No. w26867). National Bureau of Economic Research

5. Baig AS, Butt HA, Haroon O, Rizvi SAR (2021) Deaths, panic, lockdowns and US equity markets: The case of COVID-19 pandemic. Finance research letters 38:101701

6. Baker SR, Bloom N, Davis SJ, Kost K, Sammon M, Viratyosin T (2020) The unprecedented stock market reaction to COVID-19. The review of asset pricing studies 10(4):742-758

7. Bhosale J (2020) Prices of agricultural commodities drop 20\% post COVID-19 outbreakrediffRealtime News

8. Bloom E, De Wit V, Carangal-San Jose MJ (2005)Potential economic impact of an avian flu pandemic on Asia

9. Boyle PP (1977) Options: A monte carlo approach. J Financ Econ 4(3):323-338

10. Chen WC, Huang AS, Chuang JH, Chiu CC, Kuo HS (2011) Social and economic impact of school closure resulting from pandemic influenza A/H1N1. J Infect 62(3):200-203

11. Chiang TC, Jeon BN, Li H (2007) Dynamic correlation analysis of financial contagion: Evidence from Asian markets. J Int Money Finance 26(7):1206-1228

12. Chinhamu K, Huang CK, Huang CS, Chikobvu D (2015) Extreme risk, value-at-risk and expected shortfall in the gold market. International Business \& Economics Research Journal (IBER) 14(1):107122

13. Cujean J, Hasler M (2017) Why does return predictability concentrate in bad times? J Finance 72(6):2717-2758

14. Das NM, Rout BS (2020) Impact of COVID-19 on Market Risk: Appraisal with Value-at-risk Models. The Indian Economic Journal 68(3):396-416

15. Escanciano JC, Olmo J (2010) Backtesting parametric value-at-risk with estimation risk. Journal of Business \& Economic Statistics 28(1):36-51

16. Ferguson NM, Laydon D, Nedjati-Gilani G, Imai N, Ainslie K, Baguelin M, Hinsley W (2020) Impact of non-pharmaceutical interventions (NPIs) to reduce COVID-19 mortality and healthcare demand. Imperial College COVID-19 Response Team. Imperial College COVID-19 Response Team, 20

17. Gaglianone WP, Lima LR, Linton O, Smith DR (2011) Evaluating value-at-risk models via quantile regression. Journal of Business \& Economic Statistics 29(1):150-160

18. Gil-Alana LA, Claudio-Quiroga G (2020) The COVID-19 impact on the Asian stock markets. Asian Economics Letters 1(2):1-5

19. Ilyas A (2020) Covid-19 pandemic: emergence of a new geopolitical perspective 
20. Jenny F (2020) Economic resilience, globalization and market governance: Facing the Covid-19 test. Globalization and Market Governance: Facing the COVID-19 Test (March 28, 2020)

21. Jordà Ò, Singh SR, Taylor AM (2020) Longer-run economic consequences of pandemics?The Review of Economics and Statistics, 1-29

22. Jorion $P$ (1996) Risk2: Measuring the risk in value at risk. Financial analysts journal 52(6):47-56

23. Kumar VV (2020) Global pandemic due to pandemic inevitable, but recovery can be fast. Economic Times

24. Lee JW, McKibbin WJ (2004) Globalization and disease: The case of SARS. Asian Economic Papers 3(1):113-131

25. Liu H, Manzoor A, Wang C, Zhang L, Manzoor Z (2020) The COVID-19 outbreak and affected countries stock markets response. Int J Environ Res Public Health 17(8):2800

26. Mazur M, Dang M, Vega M (2021) COVID-19 and the march 2020 stock market crash. Evidence from S\&P1500. Finance Research Letters 38:101690

27. McKibbin WJ, Sidorenko A (2006) Global macroeconomic consequences of pandemic influenza. Lowy Institute for International Policy, Sydney, p 79

28. Mogaji E (2020) Financial vulnerability during a pandemic: insights for coronavirus disease (COVID19). Mogaji, pp 57-63

29. Nicola M, Alsafi Z, Sohrabi C, Kerwan A, Al-Jabir A, losifidis C, Agha R (2020) The socio-economic implications of the coronavirus pandemic (COVID-19): A review. Int J Surg 78:185-193

30. Patra B, Padhi P (2015) Backtesting of value at risk methodology: Analysis of banking shares in India. Margin: The Journal of Applied Economic Research 9(3):254-277

31. Prem K, Liu Y, Russell TW, Kucharski AJ, Eggo RM, Davies N, Klepac P (2020) The effect of control strategies to reduce social mixing on outcomes of the COVID-19 epidemic in Wuhan, China: a modelling study. The Lancet Public Health 5(5):e261-e270

32. Sohrabi C, Alsafi Z, O'neill N, Khan M, Kerwan A, Al-Jabir A, Agha R (2020) World Health Organization declares global emergency: A review of the 2019 novel coronavirus (COVID-19). Int J Surg 76:71-76

33. Sun J, Hou JW (2019) Monetary and financial cooperation between China and the One Belt One Road countries. Emerging Markets Finance and Trade 55(11):2609-2627

34. Uylangco K, Li S (2016) An evaluation of the effectiveness of Value-at-Risk (VaR) models for Australian banks under Basel III. Aust J Manage 41(4):699-718

35. Wen F, Xu L, Ouyang G, Kou G (2019) Retail investor attention and stock price crash risk: evidence from China. Int Rev Financial Anal 65:101376

\section{Figures}




\section{Overall Returns}

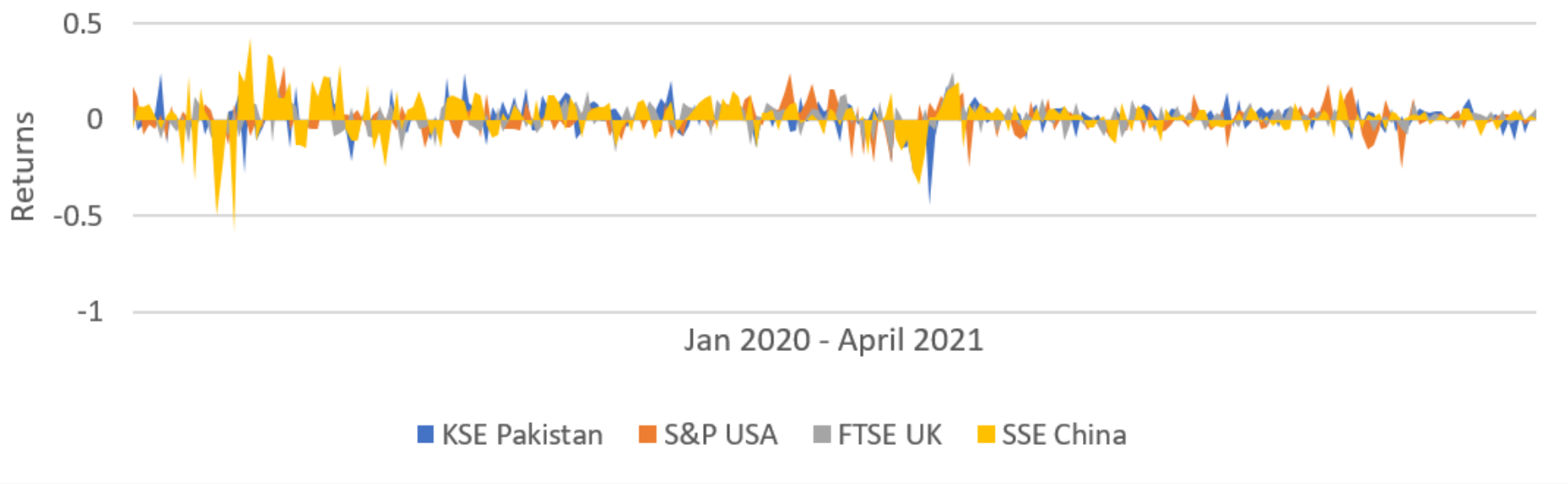

\section{Figure 1}

Graph of overall returns

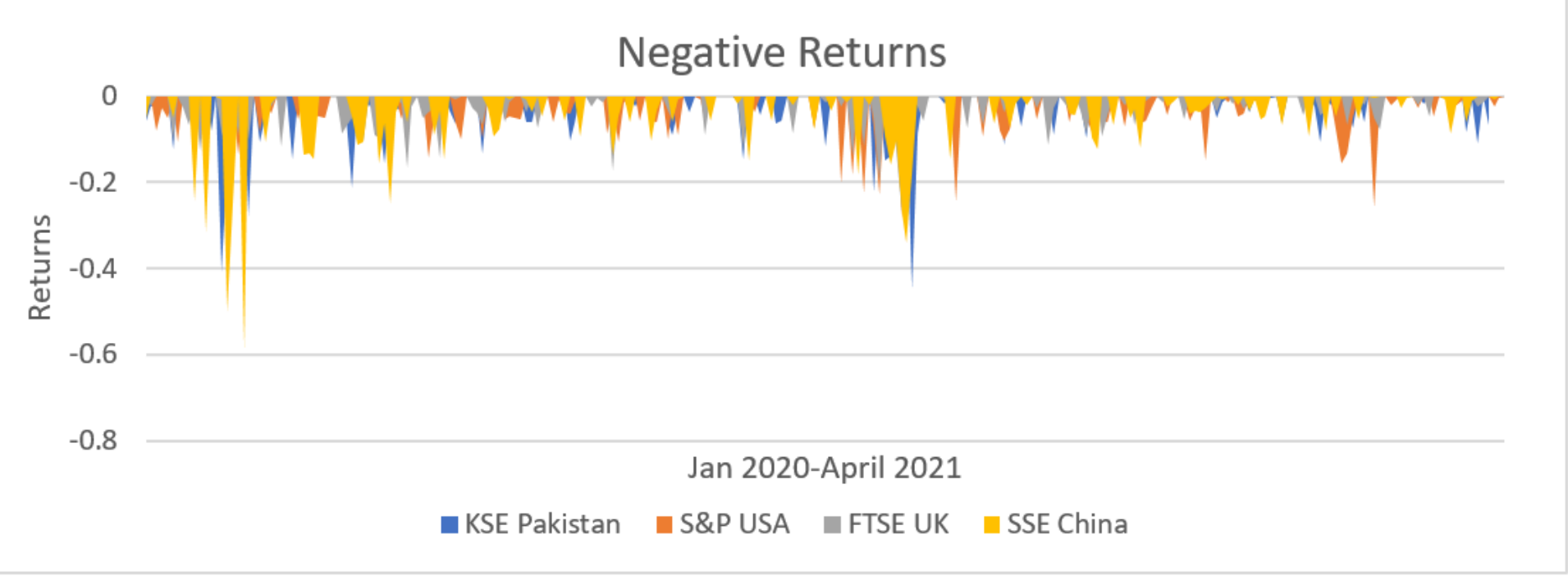

Figure 2

Graph of negative returns 


\section{Positive Returns}

0.6

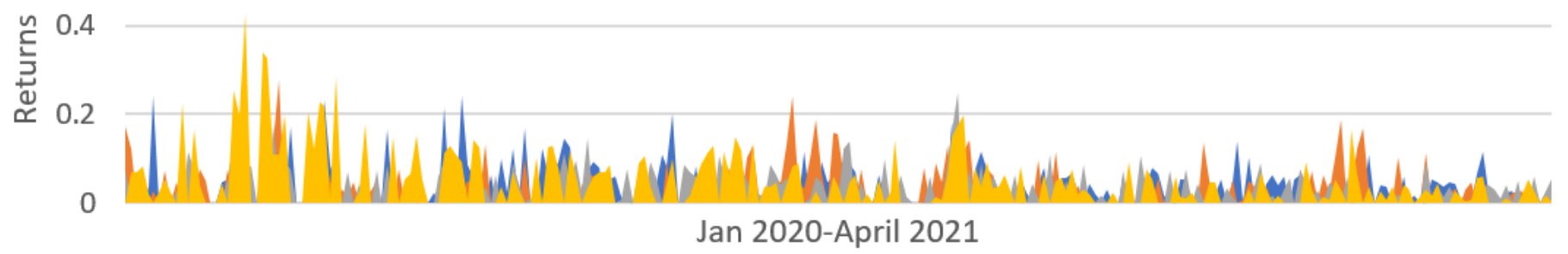

- KSE Pakistan $\quad$ S\&P USA $\quad$ FTSE UK $\quad$ SSE China

Figure 3

Graph of positive returns 